\title{
Evaluation of Regional Agricultural Circular Economy Development Based on BPEIR Concept Model
}

\author{
Guozhen Sun \\ Jilin radio and TV University, Changchun City, Jilin Province, China
}

Keywords: Agricultural Circular Economy, BPEIR Model, Delphi Method.

\begin{abstract}
Since the reform and opening up, China's economic growth is very rapid, but the extensive mode of high input, high energy consumption and high pollution growth exacerbated the country's lack of resources, environmental pollution and ecological damage rate, population growth, resource scarcity, ecological damage is becoming the three fundamental problems restricting China's modern agriculture development. The introduction of agricultural circular economy development theory into the development of modern agriculture has become the consensus of the national level and the community. This study takes the agricultural area of Huang Huai plain in our country as the research object, and uses BPEIR model and Delphi method to give a comprehensive evaluation of the development of agricultural circular economy in this region, and puts forward relevant development proposals.
\end{abstract}

\section{Introduction}

Since the reform and opening up, the construction of agricultural modernization has made a breakthrough, but the consequent destruction of agricultural ecological environment and agricultural problems such as excessive consumption of resources has become a difficult problem of restricts the development of agricultural modernization in china ${ }^{[1]}$.Using the circular economy to realize the sustainable development of agriculture has reached a general consensus at the government and all levels of society.

\section{The Connotation of Agricultural Circular Economy}

Agricultural circular economy is the concrete application of circular economy in the field of agriculture, is a kind of agricultural sustainable development concept as a guide, to introduce the theory of circular economy and agricultural production practice, in order to achieve energy-saving emission reduction and efficiency as the main target, focusing on economic growth, social benefits and ecological environment coordinated progress, finally realizes the waste recycling and energy saving the production of low carbon cycle and efficient utilization of the integration of economic development goals ${ }^{[2]}$. Agricultural circular economy as an integrated system of economic, ecological and social integration, have the following three characteristics: one is the economic characteristics, linear flow model will be upgraded to the traditional agricultural circulation mode of reciprocating flow, by reducing the agricultural development of the material energy inputs and extend the investment in agricultural production and circulation process the ecological system, to improve the level of agricultural output. two is the ecological characteristics, namely, energy saving and low carbon cycle using modern high technology, in the realization of the sustainable use of resources at the same time, to ease the continued deterioration of the ecological environment to realize sustainable development of agriculture. three social characteristics, i.e. comply with the law of social development and economic growth mode change, and achieve economic, ecological and social efficiency in the framework of natural law Make a win-win situation. 


\section{Empirical Study -- Taking Huang HuaiPlain Agricultural Area as an Example.}

At present, the overall development trend of agriculture in China is better, but the differences between regions are obvious, especially in the central and western regions and the eastern coastal areas. Since the purpose of this study is to explore the role of agricultural circular economy in the development of modern agriculture, the Huang Huai plain area, which has relatively good agricultural development, is chosen as the object of empirical study. Huang Huai Ping Yu Lusu Anhui locates in the junction of four provinces, is the most fertile soil in North China Plain, the lowest elevation in the Plains region, the agricultural economy is relatively developed, crops of wheat, soybean, corn and cotton. This study will use the Huang Huai plain area of the wheat grain production as the basis of research data, using BPEIR model and construct the evaluation index system of agricultural circular economy development combined with Delphi method to evaluate the current situation of agricultural circular economy development in the region.

Constructing Evaluation Index System of Regional Agricultural Circular Economy Development. According to relevant data, this study will follow four basic principles in constructing the system model: one is comprehensive and representative. two is the scientific and practical principles of unity. three is the comparability and reliability of the principle of unity. the four is the principle of system and the level of unity ${ }^{[3]}$. In the part of empirical research, will be devoted to introducing Delphi method to coordinate the construction and analysis of BPEIR model.

This study will use the Huang Huai plain agricultural area as an example, in Shandong Province, Heze, Anhui Province, Huaibei of Henan Province, Shangqiu, Jiangsu Province, Xuzhou of the four prefecture level cities, were screened in five major categories of indicators and sixteen one-way factors, specific empirical research (see Table 1).

Table 1 evaluation index and weight of agricultural circular economy development in Huang Huai plain area

\begin{tabular}{|c|c|c|c|}
\hline Index classification & Weight & Individual index & Individual index weight \\
\hline \multirow[t]{3}{*}{ Resource output index } & \multirow[t]{3}{*}{0.278} & Cultivated land yield / yuan $\cdot \mathrm{hm}^{-2}$ & 0.578 \\
\hline & & $\begin{array}{l}\text { Grain per unit area per } \\
\text { million } / \mathrm{kg} \cdot \mathrm{hm}^{-3}\end{array}$ & 0.310 \\
\hline & & Fertilizer utilization factor / yuan $\cdot \mathrm{kg}^{-1}$ & 0.112 \\
\hline \multirow[t]{4}{*}{$\begin{array}{l}\text { Resource } \\
\text { index }\end{array}$} & \multirow[t]{4}{*}{0.278} & $\begin{array}{ll}\text { Fertilizer } & \text { application } \\
\text { intensity } / \mathrm{kg} \cdot \mathrm{hm}^{-2} & \end{array}$ & 0.335 \\
\hline & & Pesticide use level $/ \mathrm{kg} \cdot \mathrm{hm}^{-2}$ & 0.166 \\
\hline & & $\begin{array}{l}\text { The use level of plastic } \\
\text { sheeting } / \mathrm{kg} \cdot \mathrm{hm}^{-2}\end{array}$ & 0.166 \\
\hline & & $\begin{array}{llll}\text { Proportion } & \text { of } & \text { water } & \text { saving } \\
\text { irrigation/\% } & & & \end{array}$ & 0.333 \\
\hline \multirow{3}{*}{$\begin{array}{l}\text { Comprehensive } \\
\text { utilization index of } \\
\text { resources }\end{array}$} & \multirow[t]{3}{*}{0.344} & Wheat straw utilization /\% & 0.385 \\
\hline & & Multiple crop index /\% & 0.230 \\
\hline & & Methane reserves per unit & 0.385 \\
\hline Resource & 0.033 & Per capita arable land $/ \mathrm{hm}^{2}$ & 0.333 \\
\hline \multirow{5}{*}{$\begin{array}{l}\text { environment safety index } \\
\text { Economic and social } \\
\text { development indicators }\end{array}$} & \multirow{5}{*}{0.069} & Effective irrigation coefficient /\% & 0.667 \\
\hline & & Per capita agricultural added value/ & 0.383 \\
\hline & & Per capita grain output $/ \mathrm{kg}$ & 0.320 \\
\hline & & $\begin{array}{l}\text { The average income of farmers in the } \\
\text { region/ yuan }\end{array}$ & 0.102 \\
\hline & & $\begin{array}{l}\text { Total power of agricultural } \\
\text { machinery / millionkW }\end{array}$ & 0.195 \\
\hline
\end{tabular}


The evaluation indexes were standardized: first, to the positive role of the development of agricultural circular economy index, the index of the numerical data, the index corresponding to the development status of circular economy better. Second, data indicators have a negative effect on the agricultural circular economy, the more numerical index small, more conducive to the development of agricultural circular economy in the region. In the standardization process, as follows:

Positive action index processing: $Z_{i}^{+}=\frac{C_{i}}{\max C_{i j}}$

Negative effect index processing: $Z_{i}^{-}=\frac{\min C_{i j}}{C_{i}}$

Among them, said the numerical data standardization is the role of index selection from the original data obtained after the representation is selected from the original data in the negative effect of index data after standardization were determined.in addition, $\mathrm{C}_{\mathrm{i}}$ is a single index of some kinds of indicators in the original value. And $\max C_{i j}$ andminC $C_{i j}$ refers to the maximum value, when the $i$ index and the minimum value.

In the calculation of evaluation index, this study considering the complexity of the system of regional agricultural recycling economy, in order to be able to clearly recognize the current situation, the need for a comprehensive evaluation on it, so we devoted to the use of the weighted function method to calculate and process. The formula is as follows:

$$
\begin{aligned}
& S_{j}=\sum_{i=1}^{n} Z_{i} . W_{i} \\
& \mathrm{~S}=\sum_{j=1}^{n} Z_{i} . W_{j}
\end{aligned}
$$

In the formula, $\mathrm{Z}_{\mathrm{i}}$ represents the standard statistics of each single index values in the table, $\mathrm{W}_{\mathrm{I}}$ and $\mathrm{W}_{\mathrm{j}}$ respectively represent weights corresponding to each single factor index and index statistics in the table. $S_{j}$ and $S$, the former refers to the classification of evaluation index of regional development of agricultural circular economy, which are representative of the comprehensive index. In the index evaluation, the larger the value of $S_{j}$ and $S$, the higher level of agricultural circular economy development and comprehensive level of in the plain area of Huang Huai ${ }^{[4]}$.

Evaluation Result of Regional Agricultural Circular Economy Development and Deep Excavation of Problems. One is the resource output indicators, the index value of 2014 is 3.8 times in 2000, which indicates that the Huang Huai plain level of agricultural circular economy has been improved. Two is the consumption index of agricultural resources, from 2000 to 2014 in the area of agricultural water-saving irrigation proportion increasing, fertilizer use intensity average annual increase in 5\% about three. Resource utilization index, the growth trend of the region rapidly, 2014 is 2.6 times in 2000.four is the resources and environment safety index, the overall index shows that the region is growing, the local government in the view of development to change the concept, strengthening the resources and environment management and control efforts. five is the local 
economy and the social development index continued to show growth, compared with 2000, an increase of nearly 3 times.

Through the comparison of indicators, we can see that the following problems exist in the development of agricultural economy in Huang Huai plain area: first, the scientific and technological content of crop production is low, and the economic value is not high. Although the regional wheat yield at the higher level of the whole country, but the area of wheat production has been involved in national and provincial grain production activities in the region science and technology projects, research and promotion of high yield cultivation techniques of grain crops are seriously lagging behind in the surrounding area. Two, the mechanism of regional industrial benefit guarantee is not perfect. In recent years, with the improvement of the national emphasis on food safety and quality issues, and began to promote the production of good quality wheat planting area, Huang Huai wheat based food crop production also towards the direction of industrialization development, but the regional industrial interests protection mechanism does not keep pace with industrialization pace, there are still a lot of the problem. Three, there is a great deal of waste of wheat straw resources. Wheat straw burning phenomenon although in recent years because of the impact of administrative means of intervention and education have signs of easing, but the accumulation of many years of bad behavior or cause at this stage there is a lot of fertile land is destroyed.

Further Application of Agricultural Circular Economy. Aiming at the development of Huang Huai plain regional agriculture and the existing problems, we can further guide the use of the theory of agricultural circular economy, to develop the essence of low carbon, environmental protection, sustainable development, low input and high output, low loss, high utilization of agricultural science and technology education, production and marketing of integrated operation mode of, from the following several aspects of work: one is by the local government or relevant departments issued the corresponding administrative policy and agricultural development policies, the use of modern science and technology, science and technology, reduce the investment in agricultural development of the material energy, the realization of agricultural resources recycling. two is the local city and County to the township as a unit and to establish a diversified platform for propaganda, increase agricultural science and education propaganda, the concept of sustainable development of agricultural circular economy to social people gradually divergent, through the establishment of circular agriculture demonstration park or demonstration base, to complete the transition from traditional agriculture to agricultural circulation. three is the science and technology research and development mode of building the school government enterprise cooperation, the introduction of advanced technological achievements in agriculture at home and abroad, pay attention to and use of agricultural scientific and technological talents for the modernization of agriculture. Provide technical support to development. four is to actively build agricultural information service platform, by the township government or by hiring some agricultural technology personnel, strengthen the agricultural technical guidance of the township and village farmers to provide personnel support for the agricultural development in the region ${ }^{[5]}$.five is the use of "Internet plus" platform to maximize market power. On the agricultural financial resources allocation to the basic role, relying on national policy support at the same time, diversification and multi direction to recruit 
private capital to participate in the construction of agricultural development, a good financial investment environment, to provide funding for agricultural growth and the development of circular economy.

\section{Conclusion}

In short, the development concept of agricultural circular economy in the development of agricultural industrialization and the establishment of a regional ecological agriculture benign circulation system, for the realization of modern agriculture with low investment and high yield development goals of low loss, high utilization, promote the sustainable development of modern agriculture will produce far-reaching effect substantial.

\section{Acknowledgements}

Project Fund: Research on Innovative Practice of the Cultivation Pattern of New-type Professional Farmers in Jilin Province. The General Topic of the Research on the Teaching Reform of Vocational Education and Adult Education in Jilin Province Project Number: 2016ZCY074.

\section{References}

[1]Wang Huogen, ZhaiHongyi. Review and Prospect of agricultural circular economy. Journal of Huazhong Agricultural University (SOCIAL SCIENCE EDITION), 2016, (4): 59-66.

[2]Wang Qi. The dilemma and way out of agricultural circular economy in China from the perspective of stakeholders. Anhui agricultural science, 2015, (19): 315-317.

[3] Li Yong. Study on the development of agricultural circular economy. Shaanxi agricultural science, 2015,61 (7): 92-94.

[4]Ma Dingchou, Wang Wenlve, Ma Lirong. Diagnosis and Countermeasures of comprehensive evaluation and restriction factors of agricultural circular economy development in Gansu. Research on agricultural modernization, 2011,32 (2): 204-208.

[5]Yin Changbin, Cheng Gang, Yang Xiaomei, et al. Path choice for sustainable agricultural development based on ecological civilization. China Agricultural Resources and regionalization, 2015,36 (1): 15-21.

[6]Yin Changbin, Cheng Gang, Yang Xiaomei, et al. Path choice for sustainable agricultural development based on ecological civilization. China Agricultural Resources and regionalization, 2015,36 (1): 15-21. 